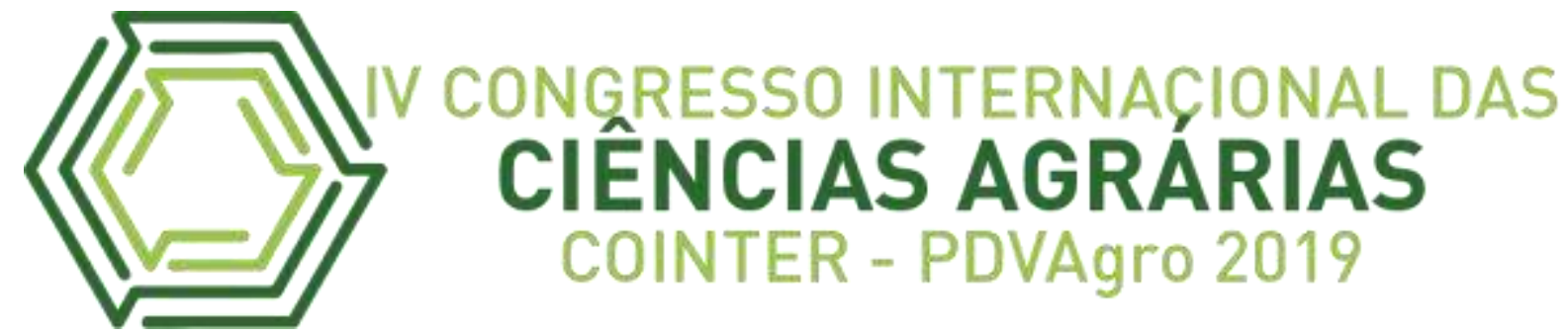

\title{
AVALIAÇÃO DOS ATRIBUTOS FÍSICOS DO SOLO SOB SISTEMA DE CULTIVO DA UVA, ENTRE LINHAS, ENTRE PLANTAS E AREA DE RENOVAÇÃO MUNICÍPIO DE SÃO VICENTE FERRER-PE
}

\author{
EVALUACIÓN DE ATRIBUTOS FÍSICOS DEL SUELO BAJO SISTEMA DE \\ CULTIVO DE UVA, ENTRE PLANTAS Y ÁREA DE RENOVACIÓN MUNICIPIO \\ DE SAN VICENTE FERRER-PE
}

\section{EVALUATION OF THE SOIL PHYSICAL ATTRIBUTES UNDER GRAPE CROPPING SYSTEM, BETWEEN, BETWEEN PLANTS AND RENEWAL AREA SÃO VICENTE FERRER-PE}

Apresentação: Comunicação Oral

José Denilson da Silva ${ }^{1}$; Sandro Augusto Bezerra ${ }^{2}$;

DOI: $\underline{\text { https://doi.org/10.31692/2526-7701.IVCOINTERPDVAgro.2019.0030 }}$

\section{Resumo}

A Videira é uma planta com grande capacidade de adaptação a diversos fatores edafoclimáticos. A denominação "uvas rústicas" ou "uvas comuns" é utilizada no Brasil para todas as cultivares de uvas americanas (Vitis labrusca e Vitis bourquina), e híbridas de diferentes espécies de Vitis. na agricultura convencional, devido à necessidade de produzir mais em menos tempo, é comum o uso de insumos e técnicas voltadas para o aumento da produção, afetando muitas vezes, negativamente o meio ambiente. A adoção de práticas de manejo e uso que contribuam para um acréscimo no conteúdo de matéria orgânica podem melhorar suas qualidades físicas, aumentando, por exemplo, a capacidade de retenção de água, tornando-se, portanto, uma estratégia importante para o manejo sustentável dos sistemas agrícolas. Este trabalho teve como objetivo avaliar a os atributos físicos do solo em cultivo de uva entre linhas, entre plantas e area de renovação de plantio, avaliando sua densidade do solo, densidade de particulas e umidade gravimétrica. A pesquisa foi desenvolvida na propriedade do Sr. Flávio localizada no município de São Vicente Férrer - PE. O Delineamento experimental utilizado foi o de parcelas subdivididas, onde os tratamentos principais foram três sistemas de uso: Cultivo de Uva entre linhas, plantas e área de renovação de plantio. E os tratamentos secundários foram quatro camadas do perfil do solo: $0-10 \mathrm{~cm}, 10-20 \mathrm{~cm}, 20-30 \mathrm{~cm}$ e $30-40 \mathrm{~cm}$. Nos resultados podemos observar uma maior valor de densidade de solo quando aumentamos a profundidade, já as

\footnotetext{
${ }^{1}$ Bacharelado em Agronomia, IFPE - Campus Vitória de Santo Antão, denisonsila@gmail.com

2 Doutor, IFPE - Campus Vitória de Santo Antão, sandro.augusto@vitoria.ifpe.edu.br
} 
densidades de partículas não diferiram estatisticamente, a umidade do solo foi maior nas camadas mais superficiais do solo, sendo explicado pelo maior de teor de material orgânica e cobertura vegetal presente nas área entre plantas.

Palavras-Chave: Atributos físicos, Manejo Sustentável, Conservação.

\title{
Resumen
}

La vid es una planta con gran capacidad de adaptación a diversos factores edafoclimáticos. El nombre de "uvas rústicas" o "uvas comunes" se usa en Brasil para todos los cultivares de uva estadounidenses (Vitis labrusca y Vitis bourquina), e híbridos de diferentes especies de Vitis. En la agricultura convencional, debido a la necesidad de producir más en menos tiempo, es común utilizar insumos y técnicas destinadas a aumentar la producción, que a menudo afectan negativamente el medio ambiente. La adopción de prácticas de gestión y uso que contribuyan a un aumento en el contenido de materia orgánica puede mejorar sus cualidades físicas, aumentando, por ejemplo, la capacidad de retención de agua, convirtiéndose así en una estrategia importante para la gestión sostenible de sistemas agricolas. El objetivo de este trabajo fue evaluar los atributos físicos del suelo en el cultivo de uva entre hileras, entre plantas y área de plantación, evaluando su densidad del suelo, densidad de partículas y humedad gravimétrica. La investigación se desarrolló en la propiedad del Sr. Flávio ubicada en São Vicente Férrer PE. El diseño experimental utilizado fue el de parcelas divididas, donde los tratamientos principales fueron tres sistemas de uso: cultivo de uva entre hileras, plantas y área de renovación de siembra. Y los tratamientos secundarios fueron cuatro capas del perfil del suelo: $0-10 \mathrm{~cm}$, $10-20 \mathrm{~cm}, 20-30 \mathrm{~cm}$ y $30-40 \mathrm{~cm}$. En los resultados podemos observar un mayor valor de la densidad del suelo al aumentar la profundidad, ya que las densidades de partículas no diferían estadísticamente, la humedad del suelo era mayor en las capas más superficiales del suelo, lo que se explica por el mayor contenido de material orgánico y la cubierta vegetal. presente en áreas entre plantas.

Palabras Clave: Atributos físicos, Gestión sostenible, Conservación.

\begin{abstract}
$\mathrm{O}$ The vine is a plant with great capacity to adapt to various edaphoclimatic factors. The name "rustic grapes" or "common grapes" is used in Brazil for all American grape cultivars (Vitis labrusca and Vitis bourquina), and hybrids of different species of Vitis. In conventional agriculture, due to the need to produce more in less time, it is common to use inputs and techniques aimed at increasing production, often negatively affecting the environment. The adoption of management and use practices that contribute to an increase in organic matter content can improve its physical qualities, increasing, for example, the water retention capacity, thus becoming an important strategy for the sustainable management of agricultural systems. The objective of this work was to evaluate the physical attributes of the soil in grape cultivation between rows, between plants and planting area, evaluating its soil density, particle density and gravimetric moisture. The research was developed in the property of Mr. Flávio located in São Vicente Férrer - PE. The experimental design used was that of split plots, where the main treatments were three systems of use: Grape Cultivation between rows, plants and planting renewal area. And the secondary treatments were four layers of the soil profile: $0-10 \mathrm{~cm}, 10$ $20 \mathrm{~cm}, 20-30 \mathrm{~cm}$ and $30-40 \mathrm{~cm}$. In the results we can observe a higher value of soil density when
\end{abstract}


we increased the depth, since the particle densities did not differ statistically, the soil moisture was higher in the most superficial soil layers, being explained by the higher organic material content and vegetation cover. present in areas between plants.

Keywords: Physical attributes, Sustainable Management, Conservation

\section{Introdução}

O Município de São Vicente Férrer, no agreste de Pernambuco, se destaca por possuir 90\% da área destinada a viticultura no agreste, plantada com uva Isabel (Embrapa, 2009). No entanto, até o momento poucos estudos foram realizados para avaliar a respeito do impacto que a substituição da mata nativa pelo cultivo da videira irrigada pode causar nos atributos físicos do solo. A uva produzida nessa região tem características peculiares devido às condições abióticas locais e à interferência do viticultor na adoção de um sistema de produção familiar. O cultivo é desenvolvido no relevo acidentado da região, com solos férteis e profundos, e em pequenas propriedades de 0,5 a 12 ha, fator que valoriza a produção e a qualidade da uva (Flores et al., 2005).

De acordo com REINERT e REICHERT, (2006) a física de solos estuda e define, qualitativa e quantitativamente, as propriedades físicas, bem como sua medição, predição e controle, com o objetivo principal de entender os mecanismos que governam a funcionalidade dos solos e seu papel na biosfera.

As propriedades físicas do solo indicam sua qualidade física, que por sua vez estão diretamente relacionadas à capacidade de infiltração, retenção e disponibilidade de agua às plantas, além de capacitar as trocas gasosas da atmosfera com as raízes e permitir o crescimento vegetal sem impedimentos (FERREIRA et al., 2010). Os indicadores mais utilizados de qualidade física do solo são a densidade, a porosidade total, infiltração de água no solo a distribuição e o tamanho dos poros, a distribuição das partículas, a resistência do solo à penetração, a profundidade efetiva de enraizamento e o intervalo hídrico ótimo (INGARAMO (2003). A densidade do solo é a propriedade física mais estudada e monitorada, e tem sido empregada para avaliar o estado estrutural do solo, além do mais, é utilizada como indicador do estado da compactação do solo (FERREIRA, et al., 2010). A compactação do solo pelo uso de práticas inadequadas de manejo resulta diretamente no aumento da densidade do solo e, por consequência, em alterações de outras propriedades como porosidade do solo, infiltração, retenção de água, e resistência do solo à penetração do sistema radicular (CAVALIERI et al. 1992). 
A densidade do solo sofre com a variação do espaço poroso do solo (Ferreira et al., 2010). Esta variável além de variar conforme o cultivo ou uso do solo, pode variar também conforme o tipo de solo como foi observado no trabalho de Silva e Ribeiro (1997), onde observaram sob solo virgem maiores valores na densidade do solo, evidenciando a origem pedogenética dos valores de densidade do solo em alguns solos.

A umidade gravimétrica do solo é uma propriedade muito importante, pois é capaz de interferir nas outras duas propriedades. Segundo Figueiredo et al., (2008) esta é um fator controlador da compactação do solo, ou seja há uma umidade ideal para o preparo do solo, que propicia a menor compactação destes. De modo geral o manejo inadequado dos solos que são utilizados nos cultivos provoca aumento na resistência à penetração e densidade do solo e consequentemente redução da porosidade e da quantidade de água disponível às plantas (RIBON \& TAVARES FILHO, 2008). O conhecimento sobre a distribuição granulométrica de partículas sólidas do solo é essencial em várias situações, como na determinação da textura, em estudos sobre compactação e movimentação de água e, consequentemente, para compreensão dos processos erosivos que envolvem transporte e deposição de partículas, inclusive de nutrientes essenciais ao desenvolvimento e produtividade das plantas (SILVA et al., 2011).

A textura de um solo não sofre alterações em um curto espaço de tempo diferentemente da estrutura que pode sofrer modificações ocasionadas pelas práticas de uso e manejo. Por apresentar rápidas modificações tanto no tempo como no espaço a estrutura do solo vem sendo utilizada como indicador da qualidade ambiental (PEREIRA \& THOMAZ, 2015). Com isso este trabalho teve como objetivo avaliar os atributos físicos do solo na cultura da videira entre plantas e entre linhas e área de renovação de plantio município de São Vicente Ferrer-PE

\section{Fundamentação Teórica}

A vitivinicultura está presente em várias regiões do Brasil, tendo porém um destaque especial para o Rio Grande do Sul, na serra gaúcha, onde quase a totalidade da produção se destina à agroindústria do suco e do vinho, sendo em sua maioria produzida por pequenos agricultores de agricultura familiar (MELLO, 2015). No tocante a produção de uvas de mesa, a cultura se destaca no Vale do São Francisco (Pernambuco e Bahia) e em São Paulo, gerando renda para milhares de famílias (MELLO, 2015).

A produção de uva na safra 2016 apresentou um leve aumento quando comparada com a produção total de uva na safra 2015 (IBGE, 2016). A região Sul, em especial o Estado do Rio 
Grande do Sul, continua com a maior participação na produção brasileira contribuindo em 2016 com $41,9 \%$ da produção na região sul, que contribuiu com $52 \%$ da produção nacional (IBGE, 2016). A região nordeste também aparece com a segunda maior participação na produção nacional com um índice de 31,3\% (IBGE, 2016).

Em relação as características da cultivar Isabel, a literatura apresenta divergências a respeito de sua origem mas sendo considerada por muitos autores como um híbrido natural entre as espécies V. labrusca e V. vinifera, pertencente, portanto, à espécie V. labruscana e que de forma inicial foi propagada no estado da Carolina do Sul, na costa leste americana (RITSCHEL, 2005).

A cultivar foi introduzida entre 1939 e 1942 no estado do Rio Grande do sul e apresentou grande expansão a qual foi possibilitada pela sua alta capacidade em se adaptar a condições climáticas (ROMBALDI et al., 2004). Além da sua fácil adaptação às condições climáticas diversas a cultivar Isabel apresenta características importantes quanto aos seus produtos destinados ao processamento, Camargo et al (2010) apresenta a rusticidade, fertilidade e abundancia de colheita como características produtivas bem como a adaptação a todos os tipos de sucos, com potencial para produção alternativa de vinho de mesa, preservando o sabor característico das labruscas.

A qualidade física de um solo está relacionada aos seus atributos físicos, que são usados como indicadores de qualidade ao refletirem a forma a qual as partículas e os espaços porosos estão organizados no solo (CUNHA NETO et al., 2018) este atributos físicos (densidade do solo, granulometria do solo, volume total de poros - macro e micro porosidade, resistência do solo a penetração) se relacionam de forma continua com os atributos químicos e biológicos de um solo, o conhecimento dos efeitos do manejo nesses atributos são conhecidos de forma isolada, se fazendo necessário os entender de forma conjunta (CARNEIRO et al., 2009).

O aumento na resistência do solo à penetração é uma das propriedades físicas do solo diretamente relacionado com o crescimento das plantas (LETEY, 1985, apud CARDOSO, 2014). O manejo incorreto de máquinas e equipamentos agrícolas leva à formação de camadas subsuperficiais compactadas dificultando a infiltração da água, aeração do perfil do solo e penetração das raízes (LOURENTE et al, 2011). A penetração da raiz da videira no perfil do solo diminui bruscamente para valores de densidade do solo superiores a $1,50 \mathrm{~g} / \mathrm{cm}^{3}$ (SOARES et al, 1998; RICHARDS, 1983). 
As plantas de cobertura utilizadas em sistemas de produção agrícola exercem funções sobre a estruturação do solo. As gramíneas possuem maior capacidade regenerativa da estabilidade da estrutura do solo, com efeitos benéficos sobre a agregação do solo, pois por apresentarem maior comprimento do sistema radicular e melhor distribuição, tendem a promover maior estabilidade do solo (SILVA, 1993; ROSA, 2008).

Segundo Sanchez, (2012), o conhecimento e o entendimento dos efeitos de determinadas plantas de cobertura numa possível melhoria das condições físicas do solo, como porosidade, densidade e resistência à penetração, é de grande importância na busca da manutenção de áreas agrícolas com condições ideais para desenvolvimento das culturas comerciais.

Em relação as propriedades físicas a compactação possui efeito direto sobre o desenvolvimento das culturas pelo impedimento mecânico causado pela penetração das raízes no solo (MARTINS et al., 2009). A alteração da estrutura do solo decorrente da compactação tem provocado efeitos negativos em suas propriedades físicas, químicas e biológicas, com prejuízos ao desenvolvimento das plantas e, consequentemente, à produção de alimentos (CAMARGO e ALLEONI, 1997). O processo de compactação do solo pode ser atribuído tanto à diminuição do espaço poroso entre os agregados, ocorrendo um rearranjamento destes na matriz do solo, como à ruptura e destruição dos agregados, havendo rearranjamento e orientação das partículas, o que resulta numa massa coesa na matriz do solo (HORN et al., 1995). Esses processos vão depender do conteúdo de água do solo e da pressão externa aplicada ao solo pelos sistemas de manejo adotados (SILVA; MAIA e BIANCHINI, 2006).

O processo de compactação é diferente do processo de adensamento do solo, este último é causado pela deposição de partículas menores nos espaços porosos, mantendo-se o volume em constância mesmo com o aumento da massa (STONE; GUIMARÃES e MOREIRA, 2002).

O manejo do solo, seu uso, os implementos, o preparo do solo, podem alterar as propriedades físicas do solo, que consequentemente, podem interferir na produção das culturas. Interferindo também, nas alterações de suas propriedades químicas e biológicas. De forma que cada produtor trabalha de maneira própria, conduzindo de forma individual as propriedades físicas, químicas e biológicas do solo cultivado. 
Segundo Sanchez, (2012), o conhecimento e o entendimento dos efeitos de para assegurar a sustentabilidade do sistema produtivo, o manejo do solo deve manter as propriedades físicas do solo o mais próximo das condições originais em que este se encontrava na natureza (LLANILLO et al,.2006). As pesquisas sobre este sistema de manejo estão em grande expansão, contudo ainda são poucas (FERNANDES et al., 2014).

\section{Metodologia}

O experimento foi desenvolvido na propriedade dos Sr. Flávio, no Município de São Vicente Ferrer Agreste Pernambucano, localizado na mesorregião do Agreste Pernambucano do Médio Capibaribe ( $7^{\circ} 35^{\prime} 27^{\prime \prime}$ S, 35 29' 27" W), localizado no agreste de Pernambuco, com altitude de $570 \mathrm{~m}$. O clima é classificado como As', quente e úmido com chuvas de outono inverno (Beltrão \& Macedo, 1994). A precipitação média anual é de $1.103 \mathrm{~mm}$, sendo a temperatura média anual de $24^{\circ} \mathrm{C}$. A vegetação nativa é típica do agreste: Florestas Subcaducifólica e Caducifólica (SÃO VICENTE FERRER, 2017).

A outra propriedade dos Srs Pedro e Evaldo onde vinha sendo realizado as atividades, foi vendida pelos mesmo, sendo assim não conseguimos contato com os novos proprietários para realizar as atividades. Assim tivemos que mudar os locais de coletas de dados e as variáveis avaliadas.

O delineamento experimental utilizado foi o de parcela subdivididas, onde os tratamentos principais foram três sistemas de manejo e uso da cobertura vegetal. Os tratamentos secundários foram quatro camadas do perfil do solo: $(0,0-0,1 \mathrm{~m} ; 0,1-0,2 \mathrm{~m} ; 0,2-0,3 \mathrm{~m}$; e 0,30,4 m.). Sendo utilizado cinco repetições em três áreas, a saber: Uva entre linhas, Uva entre plantas e Área de Renovação de parreiral.

\section{Os tratamentos principais foram:}

- UL: Uva entre linhas, variedade Isabel, implantada onde antes era uma área de Mata Atlântica. A adubação é feita com esterco bovino e também com adubos químicos, porém não é realizado analises de solo com frequência. São colhidas duas safras por ano e a dormência das plantas é controlada por poda e irrigação, o sistema de cultivo é Latada e a irrigação é feita por gotejamento. 
- UL: Uva entre plantas variedade Isabel, implantada onde antes era uma área de Mata Atlântica. A adubação é feita com esterco bovino e também com adubos químicos, porém não é realizado analises de solo com frequência

- AR: Área de renovação da cultura, onde está havendo trocas de plantas e renovação dos sistemas de irrigação, estacas e arames e preparo da área.

- As amostras utilizadas para a obtenção da densidade do solo e umidade gravimétrica foram retiradas do mesmo ponto. A densidade do solo foi realizada de acordo a metodologia de Kopeck, onde utiliza um anel de metal com bordas cortantes com volume conhecido (Embrapa,1997). Os anéis foram cravados no solo cada um em suas respectivas camadas $(0,0-$ 0,1 m; 0,1-0,2 m; 0,2-0,3 m; e 0,3-0,4 m) tendo o excesso retirado com o auxílio de um canivete. Sucessivamente os anéis foram envolvidos com um filme plástico e papel alumínio e guardados até a chegada ao laboratório para ser conservados a umidade do solo.

- No laboratório foram pesadas as amostras, para obtenção do peso úmido do solo para os cálculos da umidade gravimétrica e levadas para estufa de $105^{\circ} \mathrm{C}$ por 24 horas, enseguidas pesados novamente para obtenção do peso seco das amostras. Baseado no peso seco da amostra e o volume do anel foi calculada a densidade do solo (Equação 1) e a partir do peso do solo úmido e seco calculada a umidade gravimétrica do solo (Equação 2).
- $\quad D s=\frac{M s}{V}$
Equação 1

- Sendo,

- Ds: Densidade do solo, $\mathrm{Kg} \mathrm{dm}^{-3}$;

- Ms: Massa do solo seco, $\mathrm{Kg}$;

- V: volume do anel volumétrico, $\mathrm{cm}^{3}$.

$$
\text { - } U g=\frac{M u-M s}{M s}
$$

- Sendo,

- Ug: Umidade gravimétrica, $\mathrm{Kg} \mathrm{Kg}^{-1}$;

- $\mathrm{Mu}$ : Massa do solo úmido, $\mathrm{Kg}$;

- Ms: Massa do solo seco em estufa, Kg.

- Os efeitos do cultivo da videira nos atributos físicos do solo em relação à aos demais tratamentos foram feitas com auxílio do software estatístico SISVAR, da Universidade Federal 
de Lavras (UFLA). O teste utilizado para comparação de médias foi o teste de Tukey ao nível de $5 \%$ de probabilidade para a comparação das médias dos atributos dos solos. Ressalta-se que os resultados das análises físicas do solo não levaram em consideração a variação em profundidade nos tratamentos, mas entre os tratamentos em cada camada de solo avaliada. Todas as análises estatísticas foram realizadas com o programa estatístico SISVAR 5.1. (FERREIRA, 2011).

\section{Resultados e Discussão}

Tomando como base os dados coletado na área de renovação e uvas entre linhas e entre plantas, não apresentou-se diferença significativa nas camadas superficiais do solo, é possível observar o aumento gradual da densidade do solo partindo da camada de $0,1 \mathrm{~m}$ e chegando a 0,4 m de profundidade, estes valores médios apresentam maior proximidade nas camadas de 0,2 a 0,3 m e como esperado a camada de $0,4 \mathrm{~m}$ apresentou o maior valor de densidade o que é atribuído pelo adensamento natural do solo nas camadas mais profundas.

As médias de densidade apresentadas na tabela 1, do solo coletado das áreas de Uva entre plantas e de uva nas entrelinhas não apresentaram diferença estatística pelo teste de tukey ao nível de 5\% em nenhuma das camadas estudadas, o que é explicado pelo manejo adotado na propriedade sem uso de mecanização na área de cultivo restringindo dessa forma a passagem apenas de funcionários nas entrelinhas de cultivo bem como o tempo de exploração da cultura da uva na propriedade o qual corresponde a menos de três anos, esses resultados ao serem comparados a estudos realizados por Correchel et al., (1999) mesmo em cultura totalmente diferente evidenciam maiores valores de densidade do solo na entrelinhas em solo sob cultivo mecanizado da cultura do milho o que demonstra o aumento na densidade do solo nas entrelinhas de cultivo.

Outro fator que contribui para redução do efeito de compactação do solo nas entrelinhas de cultivo é a manutenção da vegetação onde em estudo realizado por Rosado et al., (2012) os autores concluíram que o uso de cobertura vegetal nas entrelinhas de cultivo da cultura da bananeira influência de forma positiva o comportamento dos atributos físicos do solo como a densidade.

Tabela 01. Densidade de solo $\left(\mathrm{g} \mathrm{cm}^{-3}\right)$ sob os tratamentos cultivo com Uva entre linhas(UL), Uva entre plantas (UP) e Área de renovação da cultura (AR).

\begin{tabular}{lllll}
\hline & \multicolumn{5}{c}{ Camadas $(\mathrm{m})$} \\
\cline { 2 - 5 } Tratamento & 0 a 0,1 & 0,1 a 0,2 & 0,2 a 0,3 & 0,3 a 0,4 \\
\hline
\end{tabular}




\begin{tabular}{lrrrr} 
UL & $1,59 \mathrm{Ba}$ & $1,60 \mathrm{Ba}$ & $1,60 \mathrm{Ba}$ & $2,05 \mathrm{Aa}$ \\
$\mathrm{UP}$ & $1,65 \mathrm{Aa}$ & $1,67 \mathrm{Aa}$ & $1,69 \mathrm{Aa}$ & $1,64 \mathrm{Ab}$ \\
$\mathrm{AR}$ & $1,64 \mathrm{Aa}$ & $1,62 \mathrm{Aa}$ & $1,63 \mathrm{Aa}$ & $1,70 \mathrm{Ab}$ \\
\hline $\mathrm{CV} \%$ & 2,97 & 3,63 & 5,23 & 16,8 \\
\hline
\end{tabular}

Legenda: Médias seguidas da mesma letra minúscula, na coluna, e maiúscula, na linha, não apresentaram diferença a significativa a $5 \%$ de probabilidade

Não houve estatísticas de densidade de partículas em nenhuma das áreas avaliadas e também entre as camadas, como podemos observar na tabela 2. Isso pode ser explicado pelo manejo que é utilizado na área e também na área anterior. E também pela não variação do solo (argissolo) da propriedade.

Tabela 02. Densidade de partículas $\left(\mathrm{g} \mathrm{cm}^{-3}\right)$ sob os tratamentos cultivo com Uva entre linhas(UL), Uva entre plantas (UP) e Área de renovação da cultura (AR).

\begin{tabular}{lcccc}
\hline & \multicolumn{4}{c}{ Camadas(m) } \\
\cline { 2 - 5 } Tratamento & 0,0 a 0,1 & $0,1 \mathrm{a} 0,2$ & 0,2 a 0,3 & 0,3 a 0,4 \\
\hline UL & $2,23 \mathrm{Aa}$ & $2,26 \mathrm{Aa}$ & $2,13 \mathrm{Aa}$ & $2,20 \mathrm{Aa}$ \\
UP & $2,23 \mathrm{Aa}$ & $2,33 \mathrm{Aa}$ & $2,20 \mathrm{Aa}$ & $2,20 \mathrm{Aa}$ \\
AR & $2,13 \mathrm{Aa}$ & $2,26 \mathrm{Aa}$ & $2,50 \mathrm{Aa}$ & $2,36 \mathrm{Aa}$ \\
\hline CV\% & 3,46 & 4,17 & 1,93 & 3,10 \\
\hline
\end{tabular}

Legenda: Médias seguidas da mesma letra minúscula, na coluna, e maiúscula, na linha, não apresentaram diferença a significativa a $5 \%$ de probabilidade

Na tabela 3 podemos observar que na área de cultivo da uva tanto para o solo coletado entre plantas quanto para as amostras de solo das entrelinhas de cultivo é observada a proximidade dos valores médios de umidade sendo este também um efeito da irrigação em área total, ao compararmos esses valores médios com o solo da área de renovação nas profundidades a partir dos $0,3 \mathrm{~m}$ todos os valores se aproximam demonstrando assim a capacidade dos solos de mata em manter a umidade nas camadas mais profundas. Estes mesmos resultados diferem dos valores apresentados na tabela 3, em trabalho realizado por Pereira (2017) monografia, onde a umidade do solo decresce com o aumento da profundidade.

A umidade aumenta nas entre linhas da cultura, isso está relacionado ao sistema de irrigação que está posicionado nas entre linhas e também ao esterco que é utilizado na adubação, onde ele consegue reter uma maior quantidade de agua. Ainda Segundo Guariz el al (2009) quando relacionou humidade e densidade do solo, observou que umidade do solo e densidade do solo são inversamente proporcionais. Na área de renovação da cultura mesmo sem utilização de irrigação como nas outras áreas avaliadas, apresentou valores de umidade igual ou 
semelhantes estatisticamente, isso é explicado pela deposição de matéria orgânica e cobertura vegetal presente na área e segundo Braida et al. (2006) estudando resíduos vegetais na superfície, observaram que o solo com palhada apresenta menores valores de densidade e, consequentemente, menor compactação. Segundo os autores, a palhada tem a capacidade de absorver parte da pressão exercida pelo trânsito de máquinas.

Tabela 03. Umidade Gravimétrica $\left(\mathrm{g} \mathrm{cm}^{-3}\right)$ sob os tratamentos cultivo com Uva entre linhas(UL), Uva entre plantas (UP) e Área de renovação da cultura (AR).

\begin{tabular}{lcccc}
\hline & \multicolumn{4}{c}{ Camadas(m) } \\
\cline { 2 - 5 } Tratamento & $0,0 \mathrm{a} 0,1$ & $0,1 \mathrm{a} 0,2$ & $0,2 \mathrm{a} 0,3$ & $0,3 \mathrm{a} 0,4$ \\
\hline UL & $0,12 \mathrm{Ab}$ & $0,08 \mathrm{Aa}$ & $0,12 \mathrm{Aa}$ & $0,11 \mathrm{Bb}$ \\
$\mathrm{UP}$ & $0,19 \mathrm{Ba}$ & $0,012 \mathrm{Aba}$ & $0,11 \mathrm{Ab}$ & $0,013 \mathrm{Ab}$ \\
$\mathrm{AR}$ & $0,18 \mathrm{Ba}$ & $0,11 \mathrm{Aa}$ & $0,12 \mathrm{Aa}$ & $0,13 \mathrm{Aa}$ \\
\hline CV\% & 3,62 & 4,47 & 3,93 & 4,162 \\
\hline
\end{tabular}

Legenda: Médias seguidas da mesma letra minúscula, na coluna, e maiúscula, na linha, não apresentaram diferença a significativa a $5 \%$ de probabilidade

\section{Conclusões}

1. Não houve diferença estatística na densidade de solo entre linhas e entre plantas nas camadas mas superficiais do solo, ela vai aumentando de acordo com a profundidade.

2. Entre plantas houve uma maior umidade gravimétrica do solo, porém não houve diferença estatística de densidade do solo, nas áreas avaliadas.

\section{Referências}

BRAIDA, J.A.; REICHERT, J.M.; VEIGA, M.; REINERT, D.J. Resíduos vegetais na superfície e carbono orgânico do solo e suas relações com a densidade máxima obtida no ensaio Proctor. Revista Brasileira de Ciências do Solo, v. 30, p. 605-614, 2006. 
CAMARGO, O.A. \& ALLEONI, L.R.F. Compactação do solo e o desenvolvimento das plantas. Piracicaba, Escola Superior de Agricultura “Luiz de Queiroz", 132p. 1997.

CAMARGO, U.A; MAIA, J.D.G; RITSCHEL, P. novas cultivares brasileiras de uva. Embrapa Uva e Vinho. 1.ed, Bento Gonçalves, 2010, 64.p.

CARDOSO, J.A.F. Atributos químicos e físicos do solo e matéria orgânica do solo sob mangueira irrigada e caatinga nativa na região do Vale do Submédio São Francisco. $78 f$ (Dissertação) - Universidade Federal do Vale do São Francisco, UNIVASSF, Juazeiro-BA, 2014.

CARNEIRO, M. A. C; SOUZA, E. D; REIS, E. F; PEREIRA, H. S; AZEVEDO, W. R. Atributos físicos, químicos e biológicos de solo de cerrado sob diferentes sistemas de uso e manejo. Revista Brasileira de Ciência do Solo, Viçosa, v. 33, n. 1, p. 147157, 2009.

CAVAliERI, K. M. V.; TORMENA, C. A.; VIDIGAL, P. S.; GONÇALVES, A. C. A.;CENTURION, J. F.; DEMATTÊ, J. L. I. Sistemas de preparo de solos de cerrado: efeitos nas propriedades físicas e na cultura do milho. Pesq. Agropec. Bras., Brasília, v.27, n.2, p. 315- 324, 1992.

CORRECHEL, V.; SILVA, A. P.; TORMENA, C. A. Influência da posição relativa à linha de cultivo sobre a densidade do solo em dois sistemas de manejo do solo. Revista brasileira de ciência do solo, v. 23, n. 1, 1999.

CUNHA NETO, F. V; PEREIRA, M. G; LELES, P. S. S; ABEL, E. L. S. Atributos químicos e físicos do solo em áreas sob diferentes coberturas florestais e pastagem em Além ParaíbaMG. Ciência florestal, Santa Maria, v.28, n. 1, p. 13-24, 2018.

Embrapa Semiárido. 2009. LEÃO, P.C. de S. e BORGES, R. M. E. Melhoramento genético da videira. Petrolina:, 61p. [Embrapa Semi-árido. Série Documentos,224].

FERNANDES, K. L; RIBON, A. A; HERMÓGENES, V. T .L; CUSTÓDIO, G. D e BARROS, L. R. Atributos físicos de solo sob cerrado em diferentes sistemas d e uso e manejo de pastagens e mata nativa. Cultivando o saber, v.7, n.1, p.14-23, 2014.

FERREIRA, D. F. Sisvar: a computer statistical analysis system. Ciênc. agrotec. vol.35 no.6 Lavras Nov./Dec. 2011.

FERREIRA, R. R. M.; TAVARES FILHO, J.; FERREIRA, V. M. Efeitos de Sistemas de Manejo de Pastagens nas Propriedades Físicas do Solo. Semina: Ciências Agrárias, Londrina, v. 31, n. 4, p. 913-932, out./dez. 2010.

FIGUEIREDO, C. C.; RAMOS, M. L. G.; TOSTES, R. Propriedades físicas e matéria orgânica de um LATOSSOLO VERMELHO sob sistemas de manejo e cerrado nativo. Bioscience Jornal, Uberlândia, v.24, n.3, p.24-30, jul./set. 2008. 
GUARIZ, H. R.; CAMPANHARO, W. A.; PICOLI, M. H. S.; CECÍLIO, R. A.; HOLLANDA, M. P. de. Variação da umidade e da densidade do solo sob diferentes coberturas vegetais. Revista Brasileira de Agroecologia, v. 4, n. 2, p. 3293-3296, nov. 2009.

HORN, R.; DOMZAL, H. \& OUWERKERK, C. van. Soil compaction processes and their effects on the structure of arable soils and the environment. Soil Till. Res., 35:2336, 1995.

IBGE. LEVANTAMENTO SISTMÁTICO DA PRODUÇÃO AGRÍCOLA. Rio de Janeiro. V.29 n. 12. Dezembro de 2016. ISSN: 0103-443X

INGARAMO, O. E. Indicadores físicos de la degradación del suelo. 2003. 298p. Tese (Doutorado) - Universidade da Coruña, La Coruña.

LLANILLO, R.F; RICHART, A; TAVARES FILHO, J; GUIMARÃES, M.F; FERREIRA, R. R. M. Evolução de propriedades físicas do solo em função dos sistemas de manejo em culturas anuais. Ciências Agrárias, Londrina, v. 27, n. 2, p. 205-220, 2006.

LOURENTE, E. R .P; MARCANTE, F. M.; ALOVISI, A. M. T.; GOMES, C. F.; GASPARINI, A. S.; NUNES, C. M.; ATRIBUTOS MICROBIOLÓGICOS, QUÍMICOS E FÍSICOS DE SOLO SOB DIFERENTES SISTEMAS DE MANEJO E CONDIÇÕES DE CERRADO. $e$-ISSN 1983-4063 - www.agro.ufg.br/pat - Pesq. Agropec. Trop., Goiânia, v. 41, n. 1, p. 2028, jan./mar. 2011

MARTINS, M. V; CARVALHO, M. P; ANDREOTTI, M; MONTANARI, R. Correlação linear e espacial entre a produtividade do feijoeiro e atributos físicos de um LATOSSOLO VERMELHO DISTROFFÉRRICO de Selvíria, estado de Mato Grosso do Sul. Acta Scientiarum. Agronomy, Maringá, v. 31, n. 1, p. 147-154, 2009.

MELLO, L. M. R. de. Desempenho da vitivinicultura brasileira em 2015. EMBRAPA. Disponível em: <https://www.embrapa.br/busca-de-noticias/-/noticia/9952204/artigodesempenho-da-vitivinicultura-brasileira-em-2015. Acessado em 04 de Julho de 2018.

PEREIRA, Adalberto Alves \& THOMAZ, E. L. PARÂMETROS FÍSICOS DO SOLO EM DIFERENTES SISTEMAS DE MANEJO CONVENCIONAL, MUNICÍPIO DE RESERVA - PR. Revista do Departamento de Geografia - USP, Volume 30 (2015), p. 65 a 76.

PEREIRA, R. A. Atributos físicos de um argissolo do agreste de pernambuco sob cultivo de uva, pastagem e mata nativa. 2017, 28p, (Instituto Federal de educação ciência e tecnologia de Pernambuco, campus Vitória) 2017.

REINERT, D. J.; REICHERT, R. M. Propriedades físicas do solo. Santa Maria, UFSM, 18 p., 2006.

RIBON, A. A.; TAVARES FILHO, J. Estimativa da Resistência Mecânica à Penetração de um LATOSSOLO VERMELHO sob Cultura Perene no Norte do estado do Paraná. Revista Brasileira de Ciência do Solo, v. 32, n. 5, p. 1817-1825, set./out. 2008.

RITSCHEL, P.S; MAIA, J. D. G; CAMARGO, U. A. PROGRAMA DE MODERNIZAÇÃO DA VITIVINICULTURA (MODERVITIS): Cultivares, 82 p. 2005. Disponível em: 
<http://www.agricultura.gov.br/assuntos/camaras-setoriais tematicas/documentos/camarassetoriais/viticultura-vinhos-e-derivados/anosanteriores-1/nota-tecnica-37.pdf $>$. Acesso em: 22 maio 2018.

ROMBALDI, C.V; BERGAMASQUI, M; , LUCCHETTA, L. Produtividade e qualidade de uva, cv. isabel, em dois sistemas de produção. Revista brasileira de fruticultura, Jaboticabal, V.26, n.1, p.89-91, 2004.

ROSADO, T. L; MONÇÃO, O.P; GONTIJO, I; PIRES, F. R. Efeito da cobertura vegetal nos atributos físicos de um latossolo amarelo cultivado com banana. ENCICLOPÉDIA BIOSFERA, Centro Científico Conhecer. Goiânia, v.8, n.15; p. 721-728, 2012.

SANCHEZ, E. Propriedades físicas do solo e produtividade de soja em sucessão a plantas de cobertura de inverno. (Dissertação). Universidade Estadual do CentroOeste, UNICENTROPR. Guarapuava-PR, 50.p, 2012.

SILVA, A. J. N.; RIBEIRO, M. R. Caracterização de um LATOSSOLO AMARELO sob cultivo contínuo de cana-deaçúcar no estado de Alagoas: Atributos Morfológicos e físicos. Revista Brasileira de Ciência do Solo, v. 21, n. 4, p. 677684, out./dez. 1997.

SILVA, G. J., MAIA, J. C. D. S; BIANCHINI, A. Crescimento da parte aérea de plantas cultivadas em vaso, submetidas à irrigação subsuperficial e a diferentes graus de compactação de um Latossolo Vermelho-escuro distrófico. Revista Brasileira de Ciência do Solo, Santa Maria, v. 30, p. 31-40,2006.

SILVA, I. F. Formação, estabilidade e qualidade de agregados do solo afetado pelo uso agrícola. Tese de doutorado em Ciência do Solo. Faculdade de Agronomia. Universidade Federal do Rio Grande do Sul, Porto Alegre, 186p, 1993.

SILVA, S. A.; LIMA, J. S. S.; ZUCOLOTO, M. Distribuição espacial das frações granulométricas em um Latossolo Vermelho amarelo utilizando krigagem indicativa. Engenharia na Agricultura, Viçosa, v. 19, n. 3, p. 195-202, 2011.

SOARES, J. M.; NASCIMENTO, T. Distribuição do sistema radicular de videira em vertisolo sob irrigação localizada. R. Bras. Eng. Agríc. Ambiental, Campina Grande, v.2, n.2, p.142-147, 1998.

STONE, L. F; GUIMARÃES, C. M; MOREIRA, J. A. A. Compactação do solo na cultura do feijoeiro. I: efeitos nas propriedades físico-hídricas do solo. Revista brasileira de engenharia agrícola e ambiental, Campina grande-PB, v. 6, n. 2, p, 207-212, 2002. 